\title{
M onitoring and control of particulate matter in indoor air: A review
}

\author{
Anshu G upta ${ }^{2 *}$ and M eena B handari² \\ ${ }^{1}$ Department of Applied Sciences, World Institute of Technology, Sohna, Gurgaon (Haryana), INDIA \\ ${ }^{2}$ Department of Applied Sciences, PDM College of Engineering for Women, Bahadurgarh (Haryana), INDIA \\ *Corresponding author. E-mail: anshu.dbg@gmail.com
}

\begin{abstract}
The review discusses the sources and concentrations of particulate matter in different microenvironments, their effect on human health, monitoring and their possible control measures particularly in office and residential buildings. Effect of various ventilation strategies on particulate concentration in air has been discussed. The calculations suggest that if the outdoor particle concentration is not more than 5-10 times the indoor particle generation rate, ventilation could be a very effective tool to control the indoor particle concentration. For coarse particles the choice of ventilation strategy is not very crucial, but for fine particulate slow rate of ventilation is more effective.
\end{abstract}

\section{Keywords: Particulate matter, Indoor air, Air speed, Ventilation, Fine particle}

\section{INTRODUCTION}

It's true that all of us face a variety of risks to our health due to air pollution as there is a variety of pollutants present in lower atmospheric zone, which may cause mild to severe human health hazards. Major sources of air pollutants are mainly coal combustion, diesel engines, vehicular emissions, construction, industrial smokes etc. Most of the people spend nearly $80 \%$ of their time indoors and often the air within homes, offices, and other buildings may be more seriously polluted than the outdoor air. Hence polluted indoor air presents higher risk to human health and deserves attention. Volatile organic compounds and Radon (Bhandari and Gupta, 2009, 2010) are the potential indoor air pollutants arising from sources within the building; whereas other pollutants like combustion products $\left(\mathrm{CO}, \mathrm{SO}_{2}, \mathrm{NO}_{2} \mathrm{CO}_{2}\right.$ environment tobacco smoke, fine particles), ozone etc. arise from both indoor and outdoor sources. Small particles are among the pollutants that represent one of the biggest health hazards (CAI, 2004). Particulate matter (PM) is an air pollutant consisting of a mixture of particles that can be solid, liquid or both, are suspended in the air and represent a complex mixture of organic and inorganic substances. These particles vary in size, composition and origin. The particle size for PM can vary from 0.005 $\mu \mathrm{m}$ to $100 \mu \mathrm{m}$ in diameter. All ambient PM are referred to as total suspended particulate matter (TSP). PM less than $10 \mu \mathrm{m}$ in diameter is referred to as $\mathrm{PM}_{10}$, that less than 2.5 $\mu \mathrm{m}$ in diameter as $\mathrm{PM}_{25}$ and so on. Particles less than 0.1 $\mu \mathrm{m}$ are called ultrafine particles (UFP). $\mathrm{PM}_{10}$ are inhalable and are referred to as respirable particulate matter (RPM). This work presents a discussion of various sources of
$\mathrm{PM}$ in indoor environment and its effects on human health along with a review of various monitoring studies. The effects of ventilation on deposition rates and airborne concentrations of various particle sizes are critically discussed.

\section{PARTICULATE SOURCES}

O utdoor sources: The outdoor sources of particles are coal combustion, diesel engines, vehicular emissions, windblown dust, agriculture, and construction and industrial activities such as mechanical grinding etc. PM in urban areas is mainly made up of metals, organic compounds, biological material, secondary PM (formed due to reactions of various atmospheric gases) and pure or elemental carbon. TSP may also contain fungal spores and pollen which cause allergic diseases. A major fraction of diesel particles are $\mathrm{PM}_{1}$ on which many organic compounds like carcinogenic polycyclic and nitropolycyclic hydrocarbons are adsorbed (Kittelson, 1998). Toxic elements like Arsenic contribute appreciably to the airborne particulate matter (Deb et al., 2002). Particulates, after being emitted into the atmosphere from various sources, remain suspended in the urban atmosphere for an appreciable time. Subsequently they are deposited on various near ground surfaces and on street sediments. These PM enter the indoors through various passages and pollute the indoor air too.

Indoor sources: Indoor particle sources such as tobacco smoke, cleaning, cooking etc. have an appreciable effect on indoor particle concentrations and personal exposure. Cooking and heating with solid fuels such as dung, wood, agricultural residues or coal is probably the largest source of indoor air pollution globally and nearly half the world 
continues to cook with solid fuels (WHO, 2002). Different types of office equipment (including fax machines, laser printers, ink-jet printers, scanners, and photocopying machines) have been found to emit RPM along with volatile organic compounds and ozone (Lee et al., 2001). It is currently a topic of high concern to monitor the release of UFP from hardcopy devices such as laser printers into the indoor environment. The general emission behavior of a printer can be examined by conducting emission test chamber measurements with particlecounting devices. Chamber experiments with modified laser printers operated without toner or paper also revealed UFP emissions. On the basis of these results Wensing et al . (2008) assumed the high-temperature fuser unit, instead of the toner, to be a source of UFP emission. An increase in the concentration of ozone and UFP numbers in the indoor air of a room during printing processes of a laser printer/ink-jet printer have also been observed by Kagi et al. (2007).

\section{HEALTH EFFECTS}

Exposure to PM is hazardous to health (Dockery et al., 1993). According to the World Health Organization, indoor air pollution from solid fuels ranks amongst the ten highest risks to human health in Africa and Asia (WHO, 2002). The size and the shape of the particles as well as their physico-chemical properties determine the depth of inhalation, the extent of inhalation, and the deposition rate in the airways (Yeh et al., 1976). The smaller the particle, the greater is the fraction of particles deposited in airways and lungs, and the greater is the surface area available for interaction with biological systems. Particulates larger than $10 \mu \mathrm{m}$ are generally filtered in the nose and throat and do not cause problems, but particulate matter smaller than about $10 \mu \mathrm{m}$ can settle in the bronchi and lungs and cause health problems. Timeseries epidemiological studies have shown statistical relations between health outcomes and outdoor PM concentration with mass median diameter of $<10 \mu \mathrm{m}$ in urban areas (USEPA, 1996; Vedal, 1997 and Samet et al., 2000). A statistical relation was found to exist between $\mathrm{PM}_{10}$ and hospital admissions for chronic lung diseases even in those areas which have relatively low ambient PM concentrations by Schwartz (1994) and Moolgavkar et al. (1997). More recent studies, however, indicate that smaller particles such as $\mathrm{PM}_{25}$ may be more closely linked with health effects (Schwartz et al., 1996; Borja-Aburto et al., 1998). After adjustment for $\mathrm{PM}_{25}$, Peng et al. (2008) found no statistically significant associations between coarse particulates $\left(\mathrm{PM}_{10-2.5}\right)$ and hospital admissions for cardiovascular and respiratory diseases. On the other hand $\mathrm{PM}_{25}$ leads to high plaque deposits in arteries, causing vascular inflammation and atherosclerosis-a hardening of the arteries that reduces elasticity, which can lead to heart attacks and other cardiovascular problems (Pope et al., 2002). UFP ( $\left.\mathrm{PM}_{0.1}\right)$ are still more harmful as these may pass through the lungs to affect other organs. Also fine particles are carriers of toxic air pollutants including heavy metals and organic compounds which can lead to mutations and cause cancer (Mage et al., 1996). Indoor air pollution (IAP) from biomass fuels contains high concentrations of health damaging pollutants and is associated with an increased risk of childhood pneumonia.

\section{COMPOSITION OF INDOOR FINE PARTICULATES}

The main components of $\mathrm{PM}_{25}$ are organic matter (30$60 \%)$, nitrates and sulphates (25-30\%), elemental carbon (5\%), and metals (1\%) (USEPA, 1995). Geller et al. (2002) studied the chemical composition of fine and coarse particles in indoor and outdoor air. They observed that organic carbon was the most significant component of $\mathrm{PM}_{25}$ mass concentrations both outdoors $(41 \pm 14 \%)$ and indoors $(61 \pm 17 \%)$. The average indoor-to outdoor $\mathrm{PM}_{25}$ organic carbon concentration ratio was higher than one $(1.77 \pm 0.36)$ which is due to contribution of indoor sources like cooking, waxes, cleaners, polishes, plasticizers and pesticides. As for elemental carbon indoor-to outdoor concentrations for fine PM was $0.84( \pm 0.32)$. The main source of elemental carbon is vehicular emissions outdoors which contributes substantially to indoor concentrations (Jones et al., 2000). Elemental carbon exists mostly in the ultrafine range, between $0.05-0.2 \mu \mathrm{m}$ and this size range has the highest outdoor-to-indoor penetration, varying generally from 75 to $100 \%$ (Seinfeld and Pandis, 1998).

Abt et al. (2000) studied the effect of indoor particle sources on indoor particle size distributions and concentrations. They observed that cooking, cleaning, and indoor work (characterized by movement of people etc.) significantly increased $\mathrm{PM}_{07-10}$ concentrations by $0.27,0.27$, and $0.25 \mathrm{~m}^{3} \mathrm{~cm}^{-3} \mathrm{~min}^{-1}$, respectively. Cooking was the only variable significantly associated with generation of particles less than $0.5 \mu \mathrm{m}$ in diameter. Outdoor particles of size $<10 \mu \mathrm{m}$ were found to contribute significantly to indoor particle levels. Effective penetration efficiencies ranged from 0.38 to 0.94 for $\mathrm{PM}_{0.02-0.5}$ and from 0.12 to 0.53 for $\mathrm{PM}_{0.7-10^{\circ}}$. Concentrations of various particle sizes for $\mathrm{PM}_{07-10}$ particles decreased with increasing particle size, reflecting the influence of deposition losses from gravitational settling.

\section{MONITORING}

Monitoring and control of indoor PM concentrations is important due to the fact that personal exposure monitoring studies have found only weak statistical associations between outdoor PM concentrations and 
Table 1. Respirable particulate matter concentration in various countries (World Bank, 2007).

\begin{tabular}{|c|c|c|c|}
\hline Country & $\begin{array}{c}\text { Particulate matter } \\
\left(\mu \mathrm{g} / \mathrm{m}^{3}\right) 2004\end{array}$ & Country & $\begin{array}{l}\text { Particulate matter } \\
\left(\mu \mathrm{g} / \mathrm{m}^{3}\right) 2004\end{array}$ \\
\hline Argentina & 58 & Ireland & 19 \\
\hline Australia & $12-20$ & Italy & $29-44$ \\
\hline Austria & 41 & Japan & $31-40$ \\
\hline Belgium & 28 & Kenya & 43 \\
\hline Brazil & $35-40$ & Korea, Rep & $41-50$ \\
\hline Bulgaria & 61 & Malaysia & 29 \\
\hline Canada & $13-22$ & Mexico & 51 \\
\hline Chile & 61 & Netherlands & 34 \\
\hline China & $50-125$ & New Zealand & 14 \\
\hline Colombia & 31 & Norway & 14 \\
\hline Croatia & 33 & Philippines & 39 \\
\hline Cuba & 21 & Poland & $39-43$ \\
\hline Czech Republic & 23 & Portugal & 23 \\
\hline Denmark & 21 & Romania & 18 \\
\hline Ecuador & 30 & Russian Federation & $21-22$ \\
\hline Ecuador & 23 & Singapore & 44 \\
\hline Egypt, Arab Rep. & 169 & Slovak Republic & 15 \\
\hline Finland & 21 & South Africa & $16-33$ \\
\hline France & 11 & Spain & $30-35$ \\
\hline Germany & $19-22$ & Sweden & 11 \\
\hline Ghana & 33 & Switzerland & 23 \\
\hline Greece & 43 & Thailand & 79 \\
\hline Hungary & 19 & Turkey & $46-55$ \\
\hline Iceland & 18 & Ukraine & 35 \\
\hline India & $37-150$ & United Kingdom & $15-25$ \\
\hline Indonesia & 104 & United States & $21-34$ \\
\hline Iran, Islamic Rep. & 58 & Venezuela, RB & 10 \\
\hline
\end{tabular}

personal exposure to PM.

Geller et al. (2002) measured fine $(0-2.5 \mu \mathrm{m})$ and coarse (2.5-10 $\mu \mathrm{m})$ RPM concentrations concurrently indoors and outdoors during the seasons when maximum outdoor $\mathrm{PM}$ penetration in indoor environments was expected (due to minimized use of heating/cooling systems). They found that coarse indoor concentrations were markedly lower than those outdoors with the average indoor-tooutdoor mass concentration ratio equal to $0.66( \pm 0.27)$. They also found that indoor $\mathrm{PM}_{2.5}$ levels were very similar to those measured outdoors, the average indoor-tooutdoor $\mathrm{PM}_{2.5}$ mass concentration ratio being equal to $1.03( \pm 0.29)$. In Geller's measurements outdoor concentrations could explain only about $37 \%$ of the variation of the indoor concentrations, thereby suggesting that there may be significant contributions by indoor sources to the overall indoor $\mathrm{PM}_{2.5}$ concentrations. Fine RPM concentrations contributed, on average, $74.3( \pm 11.0) \%$ of the total $\mathrm{PM}_{10}$ concentrations indoors and $61.3( \pm 13.1) \%$ of the total $\mathrm{PM}_{10}$ concentrations outdoors. Their studies revealed that indoor-to-outdoor concentrations of trace elements and metals in fine PM were well correlated, whereas this correlation was poor in the case of coarse PM.

Lai et al. (2006) performed a large population based study of indoor air concentrations of $\mathrm{PM}_{25}$, black smoke and $\mathrm{NO}_{2}$ in various European cities. Their study revealed that the characteristics of different populations, such as cultural practices and preferences and living styles, can affect the magnitude of various indoor determinants, eventually influencing the indoor exposure levels. On the other hand smoking, gas-stove usage, outdoor temperature and wind speed were found to be the common determinants of indoor fine particle concentrations.

Adgate et al. (2003) attempted to document outdoor (O), indoor (I) and personal (P) $\mathrm{PM}_{2.5}$ levels in a population of healthy non-smoking adults over multiple days and seasons for three different communities. They found I concentrations in all the localities to be higher than $\mathrm{O}$ concentrations. The $\mathrm{P}$ concentrations were even higher than I concentrations particularly in subjects with active lifestyles, which may be attributed to occupational and environmental tobacco smoke exposures outside the residences. Communities with higher household ventilation/day (through open doors and/or windows) had higher I and P concentrations of $\mathrm{PM}_{2.5}$ in all seasons. Season variability shows the lowest $\mathrm{P}$ and I concentrations during summer, which seems to be due to more hours of air conditioning/day and hence lower household ventilation/day during summer as compared 
Table 2. Ten most polluted cities by RPM (World Bank, 2007).

\begin{tabular}{lccc}
\hline $\begin{array}{l}\text { S. } \\
\text { No. }\end{array}$ & $\begin{array}{c}\text { Particulate } \\
\left(\mu \mathrm{g} / \mathrm{m}^{3}\right) \\
2004\end{array}$ & City & $\begin{array}{c}\text { City population } \\
\text { (thousands) } \\
2005\end{array}$ \\
\hline 1 & 169 & Cairo, Egypt & 11,128 \\
2 & 150 & Delhi, India & 15,048 \\
3 & 128 & Kolkata, India & 14,277 \\
4 & 125 & Tianjin, China & 7,040 \\
5 & 123 & Chongqing, China & 6,363 \\
6 & 109 & Kanpur, India & 3,018 \\
7 & 109 & Lucknow, India & 2,566 \\
8 & 104 & Jakarta, Indonesia & 13,215 \\
9 & 101 & Shenyang, China & 4,720 \\
10 & 97 & Zhengzhou, China & 2,590 \\
\hline
\end{tabular}

to spring and fall seasons.

Eight homes in the Bangkok Metropolitan Region (BMR) were investigated to study the relationship between indoor and outdoor concentration of airborne TSP and associated organochlorine pesticides (OCP). For TSP, on average, the higher levels were observed outdoors than indoors for urban area (69-95 $\mu \mathrm{g} / \mathrm{m}^{3}$ outdoors vs. 51-69 $\mu \mathrm{g} / \mathrm{m}^{3}$ indoors). For rural homes, the outdoor levels were however lower than the indoor levels suggesting the predominant influence of indoor sources activities. Overall, TSP levels in this study were lower than those observed in other studies in Thailand (Pentamwa and Oanh, 2008).

Measurements of carbon monoxide (CO) and $\mathrm{PM}_{2.5}$ in 13 households using bio-mass fuel in Gambia were done. Average 48-h $\mathrm{PM}_{25}$ concentration in the cooking area was $361 \pm 312 \mu \mathrm{g} / \mathrm{m}^{3}$ and its exposure was an estimated $219 \mu \mathrm{g} / \mathrm{m}^{3}$ for children and $275 \mu \mathrm{g} / \mathrm{m}^{3}$ for their mothers. The continuous $\mathrm{PM}_{2.5}$ concentration curve had peaks in all households representing the morning, midday, and evening cooking periods, with the largest peak corresponding to midday (Dionisio et al., 2008).

The effect of charcoal smoke exposure on risks of acute upper and lower respiratory infection (AURI and ALRI) among children under age 18 months in Santo Domingo, Dominican Republic (1991-1992) was investigated. It was observed that exposure to charcoal smoke increases the risk of ALRI in young children, an effect that is probably mediated by RPM (Bautista et al ., 2009). After adjustment for other risk factors, exposed children had no significant increase in risk of AURI but were 1.56 times more likely to develop ALRI. RPM concentrations were higher in charcoal-using households $\left(27.9 \mu \mathrm{g} / \mathrm{m}^{3}\right)$ than in noncharcoal ones $\left(17.6 \mu \mathrm{g} / \mathrm{m}^{3}\right)$, and ALRI risk increased with increased RPM exposure. Studies by Jiang et al. (2008) indicate that rural kitchen $\mathrm{PM}_{10}$ levels are three times higher than those in urban kitchens during cooking. $\mathrm{PM}_{10}$ was 6.1 times higher during cooking periods than during non cooking periods for rural kitchens. Personal $\mathrm{PM}_{2.5}$ levels for rural cooks were 2.8-3.6 times higher than for all other participant categories. $\mathrm{PM}_{2.5}$ exposures were the highest during cooking periods for both urban and rural cooks. However, rural cooks had 5.4 times higher $\mathrm{PM}_{2.5}$ levels during cooking than did urban cooks. Also rural cooks spent 2.5 times more hours per day cooking than did their urban counter parts. The combustion of incense, wood, cigarette, and candles are major sources of residential indoor particulate matter, especially in the $2.5 \mathrm{~m}$ size range and below (Fang et al., 2002, 2003; Brauer et al., 2000). Mannix et al. (1996) reported that burning incense could generate PM greater than $45 \mathrm{mg} /$ $\mathrm{g}$ burned, as compared to $10 \mathrm{mg} / \mathrm{g}$ burned for the cigarettes. Liao et al. (2006) found that incense burning had size integrated source emission rates of $0.038 \pm 0.026$ particles/second. For indoor particles ranging from 0.5 to $5 \mathrm{~m}, 62-92 \%$ is from indoor sources, including cooking, incense burning, and other residential activities. Table 1 presents the compiled data of RPM concentration in various countries in the year 2004 (World Bank, 2007).

\section{PM STUDIESIN INDIA}

Table 2 gives a list of ten most polluted cities in the world by RPM according to 2007 World Development Indicators of World Bank (2007). Four Indian cities - Delhi, Kolkata, Kanpur, and Lucknow figure in this list with RPM concentrations of $150,128,109$, and $109 \mu \mathrm{g} / \mathrm{m}^{3}$, respectively. These values are much higher than both the national and international standards. The concurrent World Health Organization (WHO) air quality guidelines

Table 3. Experimental deposition loss rates, $\lambda_{g}(/ \mathrm{hr})$ as a function of particle size and ventilation strategy (Bouilly et al., 2005).

\begin{tabular}{lcccccc}
\hline $\begin{array}{l}\text { Ventilation } \\
\text { strategy } \rightarrow\end{array}$ & \multicolumn{2}{c}{ Bottom- top } & \multicolumn{2}{c}{ Top-bottom } & \multicolumn{2}{c}{ Top- top } \\
\hline $\begin{array}{l}\text { Ventilation rate, } \\
\lambda_{\mathrm{V}}(/ \mathrm{hr}) \rightarrow\end{array}$ & $0.5 \mathrm{ach}$ & $1.0 \mathrm{ach}$ & $0.5 \mathrm{ach}$ & 1.0 ach & 0.5 ach & 1.0 ach \\
\hline $\mathrm{PM}_{0.3-3}$ & $0.53-0.86$ & $0.19-0.78$ & $0.49-1.05$ & $0.41-1.17$ & $0.20-0.65$ & $0.21-0.72$ \\
& $(0.64)$ & $(0.42)$ & $(0.73)$ & $(0.68)$ & $(0.40)$ & $(0.40)$ \\
$\mathrm{PM}_{3-10}$ & $1.10-3.72$ & $1.22-2.91$ & $1.19-3.33$ & $1.46-3.61$ & $0.87-2.90$ & $0.84-3.47$ \\
$\mathrm{PM}_{10-15}$ & $(1.96)$ & $(1.85)$ & $(1.98)$ & $(2.20)$ & $(1.59)$ & $(1.80)$ \\
\hline
\end{tabular}

Note: Values in parentheses are the averages for the respective particle size ranges. 
Table 4. Variation of I/O ratio for PM3 for top-bottom ventilation strategy for different ventilation rates $\left(\mathrm{C}_{\mathrm{i}}\right.$ at zero hours is taken equal to $24 \mathrm{~g}_{\mathrm{i}}$ ).

\begin{tabular}{|c|c|c|c|c|c|c|c|c|}
\hline \multirow{3}{*}{ t Hours } & \multicolumn{8}{|c|}{ I/O Cocentration ratio for $\mathrm{PM}_{3}$} \\
\hline & \multicolumn{4}{|c|}{$\lambda_{v}=1.0$ ach,$\lambda_{g}=0.68$, and $C_{0}=$} & \multicolumn{4}{|c|}{$\lambda_{v}=0.5 a c h, \lambda_{g}=0.73$, and $C_{0}=$} \\
\hline & $g_{i}$ & $2.5 g_{i}$ & $5 g_{i}$ & $25 g_{i}$ & $g_{i}$ & $2.5 g_{i}$ & $5 g_{i}$ & $25 g_{i}$ \\
\hline 0 & 24.00 & 9.60 & 4.80 & 0.96 & 24.00 & 9.60 & 4.80 & 0.96 \\
\hline 1 & 13.61 & 5.88 & 3.30 & 1.24 & 12.63 & 5.27 & 2.81 & 0.85 \\
\hline 2 & 8.35 & 3.99 & 2.54 & 1.38 & 7.15 & 3.18 & 1.85 & 0.79 \\
\hline 3 & 5.68 & 3.04 & 2.16 & 1.46 & 4.51 & 2.17 & 1.39 & 0.76 \\
\hline 4 & 4.33 & 2.56 & 1.96 & 1.49 & 3.24 & 1.68 & 1.17 & 0.75 \\
\hline 5 & 3.64 & 2.31 & 1.87 & 1.51 & 2.63 & 1.45 & 1.06 & 0.75 \\
\hline 6 & 3.30 & 2.19 & 1.82 & 1.52 & 2.33 & 1.34 & 1.01 & 0.74 \\
\hline 7 & 3.12 & 2.12 & 1.79 & 1.52 & 2.19 & 1.28 & 0.98 & 0.74 \\
\hline 8 & 3.03 & 2.09 & 1.78 & 1.53 & 2.12 & 1.26 & 0.97 & 0.74 \\
\hline 9 & 2.99 & 2.08 & 1.77 & 1.53 & 2.09 & 1.24 & 0.96 & 0.74 \\
\hline 10 & 2.96 & 2.07 & 1.77 & 1.53 & 2.07 & 1.24 & 0.96 & 0.74 \\
\hline 11 & 2.95 & 2.06 & 1.77 & 1.53 & 2.06 & 1.24 & 0.96 & 0.74 \\
\hline 12 & 2.95 & 2.06 & 1.77 & 1.53 & 2.06 & 1.23 & 0.96 & 0.74 \\
\hline
\end{tabular}

for $\mathrm{PM}_{10}$ are annual mean concentrations of $20 \mu \mathrm{g} / \mathrm{m}^{3}$ (World Bank, 2007). For fine particulate matter $\left(\mathrm{PM}_{25}\right)$ mean annual levels the guidelines of the European Commission, the European Parliament, US EPA, and WHO are respectively $25 \mu \mathrm{g} / \mathrm{m}^{3}, 20 \mu \mathrm{g} / \mathrm{m}^{3}, 15 \mu \mathrm{g} / \mathrm{m}^{3}$ and $10 \mu \mathrm{g} /$ $\mathrm{m}^{3}$ (Ballester et al., 2008). CPCB notification of November, 2009 on the national Ambient Air Quality Standards set a guideline of $60 \mu \mathrm{g} / \mathrm{m}^{3}$ and $100 \mu \mathrm{g} / \mathrm{m}^{3}$ repectively for annual and 24-h average of $\mathrm{PM}_{10}$, and $40 \mu \mathrm{g} / \mathrm{m}^{3}$ and $60 \mu \mathrm{g} / \mathrm{m}^{3}$ respectively for annual and 24-h average of $\mathrm{PM}_{2.5}(\mathrm{CPCB}$, 2009). Yet there are only few air quality studies particularly $\mathrm{PM}_{10}$ and $\mathrm{PM}_{2.5}$ characterization in India (TERI, 2001; Balachandran et al., 2000; Venkataraman and Kulkarni 2000; Kumar et al., 2001; Sharma et al., 2003; Sharma and Maloo, 2005; Bhanarkar et al., 2005, Ratan and Kumar 2005; Gupta and Kumar, 2006). Sharma and Maloo (2005) studied particle size distribution in terms of $\mathrm{PM}_{10}$ and $\mathrm{PM}_{25}$ and their chemical composition in the city of Kanpur, India. They concluded that the overall quality of air in Kanpur was much inferior to other cities in India and abroad. The concentrations of $\mathrm{PM}_{10}, \mathrm{PM}_{2.5}$ and heavy metals were 5-10 times higher than the corresponding values in European cities.

Gupta and Kumar (2006) studied the trends of particulate matter in four metropolitan cities in India and found that $\mathrm{PM}$ in all the four cities was higher than the prescribed standards of CPCB, India as well as WHO guidelines. They found that overall $\mathrm{PM}_{10}$ level in the four mega cities of India was showing a decreasing trend whereas the TSP showed steady levels. They attributed the improved $\mathrm{PM}_{10}$ levels to the lighter emission standards for automobiles and closing down of many industries in these cities. A relative comparison of ambient air concentration of pollutants emitted from transport sector during the years1995-2000 (without CNG) and the year 2001 (with CNG) has suggested that the air was much cleaner after the introduction of CNG. The annual average concentration of TSP came down from 405 to $347 \mu \mathrm{g} / \mathrm{m}^{3}$ but it was still beyond the permissible limits (Goyal and Sidharatha, 2003). The non decreasing trend of TSP as against decreasing $\mathrm{PM}_{10}$ trends was attributed to the large scale construction activities which contribute to particles larger than $10 \mu \mathrm{m}$. Ratan and Kumar (2005) monitored the air quality in 7 different locations in Delhi and found that the individual pollutant index for RPM is greater than TSP for industrial and commercial areas in Delhi. Delhi is the fourth most polluted city by TSP (Gadhok, Risks in Delhi) and second most polluted city by RPM in the world (Table 2). Constantly rising population levels, their haphazard distribution and growth, consequent rise in the levels of infrastructure and transportation activities needed to support them are the main reasons behind this pollution. Diesel electricity generating sets and vehicles, particularly auto rickshaws, are major sources which not only generate significant amount of air pollution, but also lead to highly uncomfortable levels of noise pollution. This polluted outdoor air penetrates inside buildings adding to the indoor air pollution.

Saksena and Uma (2008) monitored Indoor levels of TSP and RSP in an office building and just outside the building in New Delhi for over three and a half years. The mean values of indoor TSP and RSP concentrations were less than the outdoor concentrations but higher than the Indian ambient standards, and were much higher than those observed in similar micro-environments in developed countries. The variation in outdoor concentration of RSP could explain only $25 \%$ of the variation in indoor concentration. They concluded that 
Table 5. Variation of $\mathrm{I} / \mathrm{O}$ ratio for $\mathrm{PM}_{3-10}$ for top-bottom ventilation strategy for different ventilation rates $\left(\mathrm{C}_{\mathrm{i}}\right.$ at zero hours is taken equal to $24 \mathrm{~g}_{\mathrm{i}}$.

\begin{tabular}{|c|c|c|c|c|c|c|c|c|c|}
\hline \multirow{3}{*}{ t Hours } & \multicolumn{9}{|c|}{ I/O Cocentration Ratio for $\mathrm{PM}_{3-10}$} \\
\hline & \multicolumn{4}{|c|}{$\lambda_{v}=1.0$ ach, $\lambda_{g}=2.20$, and $C_{0}=$} & \multicolumn{5}{|c|}{$\lambda_{v}=0.5 a c h, \lambda_{g}=1.98$, and $C_{0}=$} \\
\hline & $\overline{g_{i}}$ & $2.5 \mathrm{~g}_{\mathrm{i}}$ & $5 g_{i}$ & $25 g_{i}$ & $0.8 \mathrm{~g}_{\mathrm{i}}$ & $g_{i}$ & $2.5 g_{i}$ & $5 g_{i}$ & $25 \mathrm{~g}$ \\
\hline 0 & 24.00 & 9.60 & 4.80 & 0.96 & 30.00 & 24.00 & 9.60 & 4.80 & 0.96 \\
\hline 1 & 3.47 & 1.63 & 1.02 & 0.53 & 4.90 & 3.97 & 1.72 & 0.97 & 0.37 \\
\hline 2 & 1.19 & 0.75 & 0.60 & 0.48 & 1.44 & 1.20 & 0.63 & 0.44 & 0.29 \\
\hline 3 & 0.94 & 0.65 & 0.55 & 0.47 & 0.96 & 0.82 & 0.48 & 0.37 & 0.27 \\
\hline 4 & 0.91 & 0.64 & 0.55 & 0.47 & 0.89 & 0.77 & 0.46 & 0.36 & 0.27 \\
\hline 5 & 0.91 & 0.64 & 0.55 & 0.47 & 0.89 & 0.76 & 0.46 & 0.35 & 0.27 \\
\hline 6 & 0.91 & 0.64 & 0.55 & 0.47 & 0.88 & 0.76 & 0.45 & 0.35 & 0.27 \\
\hline 7 & 0.91 & 0.64 & 0.55 & 0.47 & 0.88 & 0.76 & 0.45 & 0.35 & 0.27 \\
\hline 8 & 0.91 & 0.64 & 0.55 & 0.47 & 0.88 & 0.76 & 0.45 & 0.35 & 0.27 \\
\hline 9 & 0.91 & 0.64 & 0.55 & 0.47 & 0.88 & 0.76 & 0.45 & 0.35 & 0.27 \\
\hline 10 & 0.91 & 0.64 & 0.55 & 0.47 & 0.88 & 0.76 & 0.45 & 0.35 & 0.27 \\
\hline 11 & 0.91 & 0.64 & 0.55 & 0.47 & 0.88 & 0.76 & 0.45 & 0.35 & 0.27 \\
\hline 12 & 0.91 & 0.64 & 0.55 & 0.47 & 0.88 & 0.76 & 0.45 & 0.35 & 0.27 \\
\hline
\end{tabular}

indoor- outdoor relationships cannot be generalized, but are strongly dependent on factors such as type of building, ventilation, climate etc.

Concentration of fine particulate matter in other Indian cities is also well above recommended WHO levels. While industrial and vehicular emissions are the major contributors to PM concentrations in outdoor air, the domestic fuel combustion does so to the indoor air particularly in the residential areas. And it is the latter which contributes more to human exposure to $\mathrm{PM}$ as the time spent indoors is much higher than outdoors. The risk of PM exposure is even higher for women as their role in the family is of primary cook. P.R. Andresen et al. (2005) studied personal and indoor $\mathrm{PM}_{25}$ exposures for women using different kinds of cooking fuel in Mysore. They found that both personal and indoor $\mathrm{PM}_{2.5}$ exposures were much lower for LPG users $\left[71 \pm 15 \mu \mathrm{g} / \mathrm{m}^{3}\right.$ and $71 \pm 9 \mu \mathrm{g} / \mathrm{m}^{3}$, respectively] than for kerosene users $\left[111 \pm 13 \mathrm{~g} / \mathrm{m}^{3}\right.$ and $98 \pm 9 \mu \mathrm{g} / \mathrm{m}^{3}$, respectively in summers, and $177 \pm 21 \mu \mathrm{g} / \mathrm{m}^{3}$ and $155 \pm 13 \mu \mathrm{g} / \mathrm{m}^{3}$, respectively in winters]. The values for LPG users did not have much impact of seasons - these values are much lower than the kerosene users but are still higher than those found in the US (Quackenboss et al., 1989; Ozkaynak et al., 1990; Kim and Stock, 1986; Clayton et al., 1993; Rojas-Bracho et al., 2000; Jantunen et al., 2002; Adgate et al., 2003). This may be attributed to different cooking styles or more open kind of residences in India which provide an easy access to outdoor particulates to enter the houses.

In Mumbai a pilot survey of the indoor and the monitoring site (outdoor) air quality was carried out indicated good correlation between RSP at the monitoring site \& indoors during winters and summers but only a weak correlation during Monsoons (Deshpande et al., 2002). The emission

of various pollutants from industrial sources in Greater Mumbai was studied by Bhanarkar et al. (2005). Their estimates suggested that an erroneous $9.794 \mathrm{Gg} /$ year of PM was emitted into the Greater Mumbai atmosphere, out of which $19 \%$ was contributed by thermal power plants. This suggests that the industries should be more isolated from the residential and commercial sites than required by the present policy. Also the industrial workforce should be required to wear nose masks in order to protect them from RSP. The above discussion suggests a need to address the issue of fine PM, particularly $\mathrm{PM}_{2.5}$, monitoring and its effective control in the indoor air.

Studies done in Andhra Pradesh by Balakrishnan et al. (2002) revealed that the concentrations of RPM ranged from 500-2000 $\mu \mathrm{g} / \mathrm{m}^{3}$ during cooking in biomass-using households, and average 24-hr exposures ranged from $90 \pm 21 \mu \mathrm{g} / \mathrm{m}^{3}$ for non-cooks to $231 \pm 109 \mu \mathrm{g} / \mathrm{m}^{3}$ for cooks. In households using clean fuels the 24-hr exposures were around $82 \pm 39 \mu \mathrm{g} / \mathrm{m}^{3}$ (with similar exposures across household subgroups). Daily average concentrations of respirable particulates in 412 rural homes from three districts of Andhra Pradesh were recorded and the mean 24-h average concentrations ranged from $73-732 \mu \mathrm{g} / \mathrm{m}^{3}$ in gas versus solid fuel-using households, respectively. Concentrations were significantly correlated with fuel type, kitchen type, and fuel quantity. The mean 24-h average exposures ranged from $80-573 \mu \mathrm{g} / \mathrm{m}^{3}$. Among solid fuel users, the mean 24-h average exposures were the highest for women and were significantly different for men and children. Among women, exposures were the highest in the age group of 15-40 years (most likely to be involved in cooking or helping in cooking), while among men, exposures were highest in the age group of 65-80 years (most likely to be indoors). 


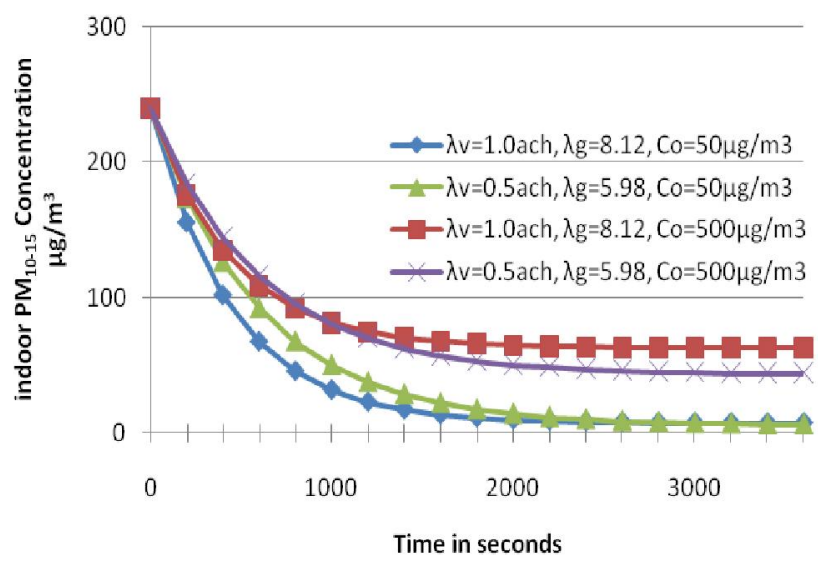

Fig. 1. Variation of $P M_{10-15}$ concentration with time with topbottom vantilation parameters : $g_{i} 10 \mu \mathrm{g} / \mathrm{m}^{3} \mathrm{~h}, \mathrm{c}_{\mathrm{i}}=240 \mu \mathrm{g} / \mathrm{m}^{3}$.

In the study by Balakrishnan et al. $(2003,2004)$ two parameters - type of fuel used and ventilation - emerged as the key determinants of exposure. Nearly $90 \%$ of the households sampled by Balakrishnan et al. (2002) in south India used solid fuel. In these households average 24-hour exposures to RPM were the highest amongst women cooks $442 \pm 37 \mu \mathrm{g} / \mathrm{m}^{3}$ compared to all the other household members. Amongst non-cooks, older women (61-80 years) experienced the highest exposures $(337 \pm 57$ $\left.\mu \mathrm{g} / \mathrm{m}^{3}\right)$, followed by children under five $\left(262 \pm 55 \mu \mathrm{g} / \mathrm{m}^{3}\right)$. This is presumably because older women remain indoors for larger periods of time. Exposures of female and male children were similar. Men of 16-60 years experienced the least exposures owing to greater likelihood of working outdoors $\left(148 \pm 5 \mu \mathrm{g} / \mathrm{m}^{3}\right)$. In households using solid fuels, kitchen configuration played an important role in affecting exposures of all household members, including children under five. Average living area RPM concentrations were the highest in households having indoor kitchens without partitions $\left(280 \pm 17 \mu \mathrm{g} / \mathrm{m}^{3}\right)$ followed by households with indoor kitchens with partitions $\left(264 \pm 17 \mu \mathrm{g} / \mathrm{m}^{3}\right)$. Enclosed outdoor kitchens or simply outdoor cooking resulted in lower levels of indoor exposure $\left(178 \pm 11 \mu \mathrm{g} / \mathrm{m}^{3}\right.$ and $175 \pm 10 \mu \mathrm{g} / \mathrm{m}^{3}$, respectively) but still exceeded national health guidelines for outdoor air pollution (24-hour Indian standard for $\mathrm{PM}_{10}$ is $100 \mu \mathrm{g} /$ $\mathrm{m}^{3}$; $\left.\mathrm{CPCB}, 2009\right)$. Thus, dispersion considerably affected indoor levels even during outdoor cooking. In households using LPG, children were exposed to three to four times lesser RPM levels $\left(76 \pm 6 \mu \mathrm{g} / \mathrm{m}^{3}\right)$ compared to solid fuel using households and these levels were similar to all the other population subgroups.

\section{INTERVENTION AND CONTROL}

In general, the smaller and lighter a particle is, the longer it will stay in the air. Larger particles ( $>10 \mu \mathrm{m}$ in diameter) tend to settle to the ground by gravity in a matter of hours whereas the smallest particles $(<1 \mu \mathrm{m})$ can stay in the atmosphere for weeks and are mostly removed by

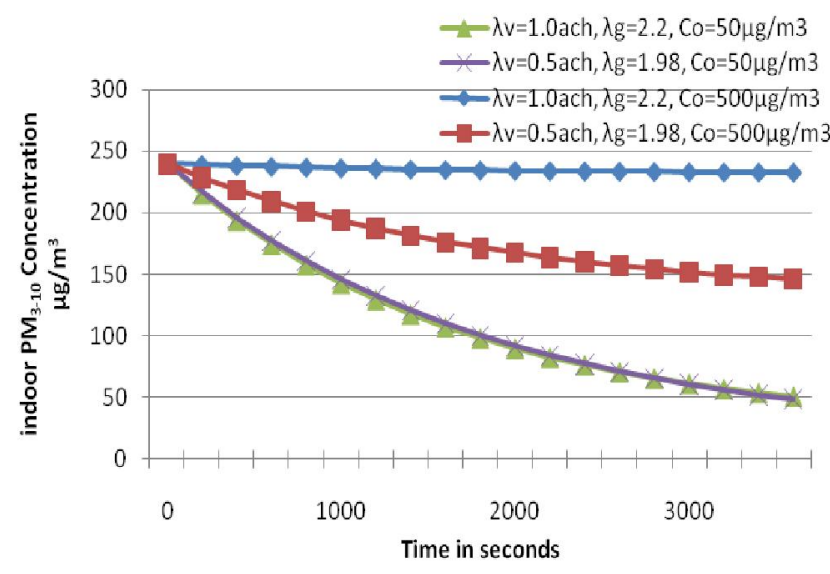

Fig. 2. Variation of $\mathrm{PM}_{3-10}$ concentration with time with top bottom vantilation parameters : $g_{i} 10 \mu \mathrm{g} / \mathrm{m}^{3} \mathrm{~h}, \mathrm{c}_{i}=240 \mu \mathrm{g} / \mathrm{m}^{3}$

precipitation. Diesel particulate matter is highest near the source of emission. Potential interventions for reducing human exposure to indoor air pollution are controlling the source (emissions), the local environment (concentrations) and the user (exposure).

Based on the evaluation it appears that for residential areas the most effective interventions and most beneficial to the user and society as a whole would be a shift from wood or charcoal to kerosene, LPG, biogas or grid electricity. Other more progressive alternatives such as ethanol (gel) fuel, or possibly biomass gasification, could not be effectively evaluated, but should be considered in greater detail in the future. Another intervention that is economic and appears to offer promising benefits is the use of a cooking window which is a form of hood built into a window (an alternate to chimney). However, this needs further investigation and evaluation for its applicability to a range of different housing types (Tremeer et al., 2000).

Indoor particle sources such as tobacco smoke and cooking vapours can have a great effect on personal exposure (Abt et al., 2000). Particle deposition on surfaces and adapted ventilation strategy can substantially reduce indoor particle concentrations (Bouilly et al., 2005; Wallace, 1996; Lai, 2002). The indoor particle deposition rate is influenced by the properties of the deposition environment such as size and shape of the room, roughness of surfaces, airflow rates, inlet/outlet locations, surface-to-air temperature difference, furniture in the room, etc. (Nazaroff et al., 1993; Abadie et al., 2001; Jamriska et al., 2000; Mundt, 2001; Nomura et al., 1997; Fogh et al ., 1997; Zhao et al., 2004; Thatcher et al ., 2002). But most of all it depends on the particle mass which directly depends on particle size. To evaluate the particle concentration evolution within a room, under isothermal conditions, the mass balance of the pollutant can be written as a function of the incoming polluted air, the particle deposition on the walls, the mass of pollutant 


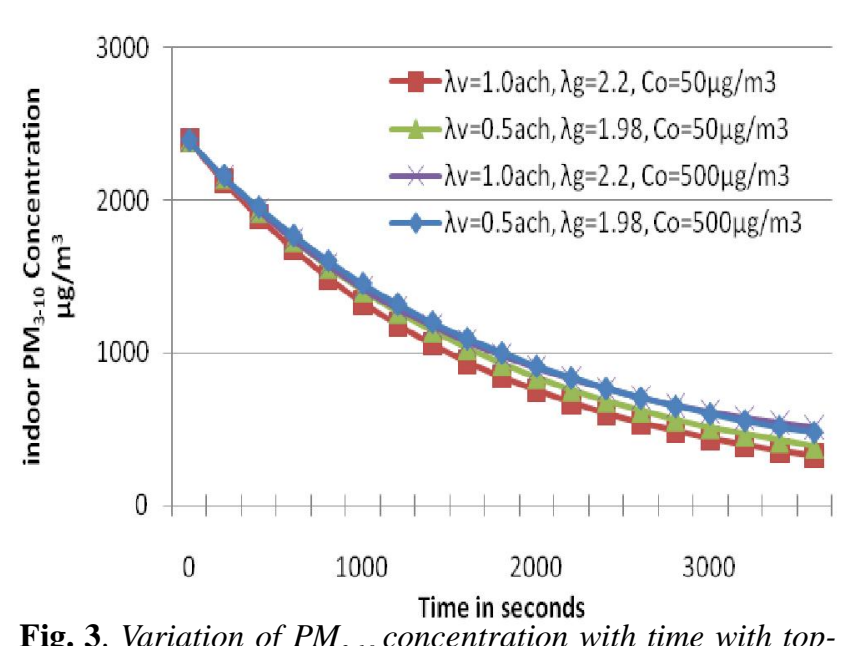

Fig. 3. Variation of $P M_{3-10}$ concentration with time with topbottom vantilation parameters : $g_{i} 100 \mu \mathrm{g} / \mathrm{m}^{3} \mathrm{~h}, \mathrm{c}_{\mathrm{i}}=2400 \mu \mathrm{g} / \mathrm{m}^{3}$ leaving the zone, and particle generation and coagulation in the room. Bouilly et al. (2005) presented a model for ventilation effects on indoor particulate concentration ignoring the last of these factors, i.e., particle generation and coagulation in the room. They found that the ventilation acts differently on different particle size: the smaller the particles are, the more important the ventilation strategy is on particle deposition velocity (Bouilly et al., 2005). They found that the influence of inlet/outlet locations is stronger for fine particles $(<5 \mu \mathrm{m}$ in diameter $)$ than for coarse particles and that an increase of ventilation rate does not necessarily lead to higher deposition. Thus RPM could effectively be controlled by a careful choice of ventilation strategy.

\section{VENTILATION MODELING}

Taking particle generation rate due to indoor sources $\left(\mathrm{g}_{\mathrm{i}}\right.$ $\mu \mathrm{g} / \mathrm{m}^{3} \mathrm{~h}$ ) also into consideration in the model of Bouilly et al. (2005), the time-dependent particle concentration can be written as

$$
\frac{d C_{i}(t)}{d t}=\lambda_{v} C_{o}(t)-\lambda_{v} C_{i}(t)-\lambda_{d \theta} C_{i}(t)+g_{i}
$$

Where $\mathrm{t}$ is the time in hours $(\mathrm{h}), \mathrm{C}_{\mathrm{i}}(\mathrm{t})$ and $\mathrm{C}_{\mathrm{o}}(\mathrm{t})$ are, respectively, the indoor and outdoor particle concentrations $\left(\mathrm{m}^{-3}\right)$ at time $\mathrm{t}, \lambda_{\mathrm{v}}$ is the air change rate $\left(\mathrm{h}^{-1}\right)$, and ${ }_{\mathrm{de}}$ is the particle deposition loss rate coefficient $\left(\mathrm{h}^{-1}\right)$.

Thus

$$
\frac{d C_{i}(t)}{d t}=\left[\frac{d C_{i}(t)}{d t}\right]_{+}-\left[\frac{d C_{i}(t)}{d t}\right]_{-}
$$

where

$$
\left[\frac{d C_{i}(t)}{d t}\right]_{+}=\lambda_{v} C_{o}(t)+g_{i}
$$

is the gain in indoor particulate concentration per unit time,

and $\quad\left[\frac{d C_{i}(t)}{d t}\right]_{-}=\lambda_{v} C_{i}(t)+\lambda_{d \theta} C_{i}(t)$

is the loss in indoor particulate concentration per unit time.

If we consider $\mathrm{C}_{\mathrm{o}}(\mathrm{t})$ to be constant with respect to time,

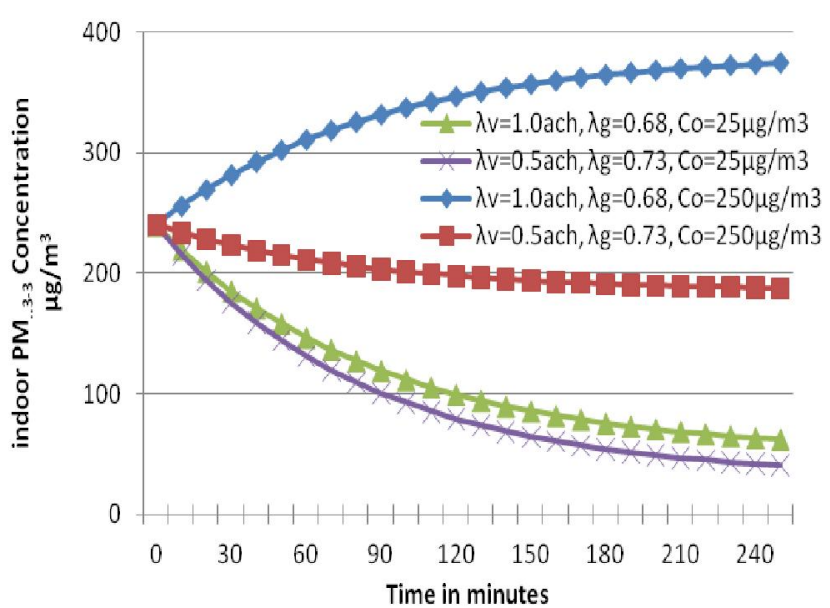

Fig. 4. Variation of $\mathrm{PM}_{3}$ concentration with time with top-bottom vantilation parameters : $g_{i} 100 \mu \mathrm{g} / \mathrm{m}^{3} \mathrm{~h}, \mathrm{c}_{\mathrm{i}}=240 \mu \mathrm{g} / \mathrm{m}^{3}$

then the gain rate/volume may be taken a constant, $\mathrm{K}_{\mathrm{g}}$ (say), i.e.,

$$
\left[\frac{d C_{i}(t)}{d t}\right]_{+}=\lambda_{v} C_{o}(t)+g_{i}=K_{g}
$$

Also we can write $\left[\frac{d C_{i}(t)}{d t}\right]_{-}=\lambda_{g} C_{i}(t)$

where $\lambda_{\mathrm{g}}=\lambda_{\mathrm{v}}+{ }_{\text {de }}$ represents the overall loss rate $\left(\mathrm{h}^{-1}\right)$. In a non-ventilated room, $\lambda_{\mathrm{v}}=0$;

therefore, $\quad \frac{d C_{i}(t)}{d t}=g_{i}-\lambda_{d \theta} C_{i}(t)$

Whereas in a ventilated room,

$$
\frac{d C_{i}(t)}{d t}=K_{g}-\lambda_{g} C_{i}(t)
$$

On integrating we get, where $C_{i}(0)$ is the indoor concentration at the time of switching on the ventilation. This gives

$$
\begin{aligned}
& C_{i}(t)=\frac{K_{g}}{\lambda_{g}}\left[1-e^{-\lambda_{g} t}\right]+C_{i}(\mathbf{0}) e^{-\lambda_{g} t} \\
& \mathrm{~K}_{\mathrm{g}} \text { being given by eq. (5). } \\
& \text { or } \quad C_{i}(t)=C_{i}(t)_{+}+C_{i}(t)_{-} \\
& \text {such that } \quad C_{i}(t)_{+}=\frac{K_{g}}{\lambda_{g}}\left[1-e^{-\lambda_{g} t}\right] \\
& \text { and } \quad C_{i}(t)_{-}=C_{i}(0) e^{-\lambda g^{t}}
\end{aligned}
$$

Bouilly et al. (2005) measured the deposition loss rates $\left(\lambda_{\mathrm{q}}\right)$ for various particle sizes and ventilation strategies. Their results are summarized in Table 3. These data suggest that the highest loss rates for RPM are obtained with top-bottom ventilation. For larger particles topbottom ventilation gives slightly lower deposition loss rate than other ventilation strategies.

Using eq. (8) and the mean values of $\lambda_{g}$ obtained by Bouilly et al. (2005) for top-bottom ventilation, the variation of indoor particle concentration with time has been plotted for various values of ventilation rate $\left(\lambda_{\mathrm{v}}\right)$, outdoor concentration $\left(C_{0}\right)$, and indoor particle generation rate $\left(g_{i}\right)$. Fig. 1 shows the variation of indoor 
coarse particles $\left(\mathrm{PM}_{10-15}\right)$ with ventilation for indoor generation rate of $10 \mathrm{~g} / \mathrm{m}^{3}$ and an indoor concentration of $240 \mathrm{~g} / \mathrm{m}^{3}$ when the ventilation is started. The plot suggests that although the concentration decreases faster with higher ventilation rate (1.0 air change per hour) in the beginning but after an hour of ventilation result is slightly better for lower ventilation rate $(0.5 \mathrm{ach})$. The indoor coarse particle concentration decreases by $\sim 97 \%$ if the $\mathrm{I} / \mathrm{O}$ concentration ratio is $\sim 5$ and by $\sim 75 \%$ for $\mathrm{I} / \mathrm{O}$ ratio of $\sim 0.5$.

Figs. 2 and 3 show similar plots for $\mathrm{PM}_{3-10}$ for initial indoor concentrations of $240 \mu \mathrm{g} / \mathrm{m}^{3}$ and $2400 \mu \mathrm{g} / \mathrm{m}^{3}$, respectively. If the outdoor concentration is lower than the indoor concentration, the ventilation rate is immaterial and the indoor concentration decreases to $\sim 20 \%$ for $0.5 \mathrm{ach}$ as well as $1.0 \mathrm{ach}$. However if the outdoor concentration is higher than the indoor concentration, higher ventilation rate is ineffective, whereas with slow ventilation the indoor concentration decreases by a moderate factor. Ventilation affects the fine particles $\left(\mathrm{PM}_{3}\right)$ quite differently (Fig.4). If outdoor concentration is lower than the indoor concentration, the latter decreases slowly for both fast and slow ventilation rates. For an initial I/O ratio of $10: 1$, it takes $\sim 60 \& 90 \mathrm{~min}$. for the indoor concentration to decrease to half the initial level for $0.5 \mathrm{ach}$ and 1.0 ach ventilation rates, respectively. On the other hand if the outdoor concentration is of the order of the indoor concentration, the latter decreases marginally for 0.5 ach ventilation rate, whereas it increases (to $\sim 150 \%$ in $2 \frac{1}{2}$ hours) for 1ach ventilation rate.

Tables 3 and 4 give the variation of I/O ratio with time for $\mathrm{PM}_{3}$ and $\mathrm{PM}_{3-10}$ for top-bottom ventilation strategy for two different ventilation rates for various ratios of outdoor concentration and indoor generation rate. Indoor concentration $\left(\mathrm{C}_{\mathrm{i}}\right)$ at zero hours is taken equal to $24 \mathrm{~g}_{\mathrm{i}}$ assuming one full day of closed doors (no ventilation) and zero deposition owing to various activities like cleaning etc. before switching on the ventilation. The calculations suggest that both slow and fast ventilation reduce the PM I/O ratio with time for all particle sizes; except for fine particles $\left(\mathrm{PM}_{3}\right)$ in the event of the outdoor concentration being twenty five times or more as high as indoor generation rate. However, in all the cases the slow ventilation is more effective.

Let us compare these calculations with some observed results. The measurements of Geller et al. (2002) gave an average indoor-to-outdoor $\mathrm{PM}_{25}$ mass concentration ratio of $1.03( \pm 0.29)$. This is in agreement with the $\mathrm{I} / \mathrm{O} \mathrm{PM}_{3}$ mass concentration ratios obtained by our model for 0.5 ach ventilation rate after 12 hours of ventilation when the outdoor concentration is more than the indoor $\mathrm{PM}_{3}$ generation rate $\left(\mathrm{C}_{\mathrm{o}}=2.5 \mathrm{~g}_{\mathrm{i}}\right.$ to $25 \mathrm{~g}_{\mathrm{i}}$; see table 4). This suggests that the 0.5 ach top-bottom mechanical ventilation may be considered equivalent to the natural ventilation of the houses monitored by Geller et al. (2002). The I/O $\mathrm{PM}_{3-10}$ mass concentration ratios obtained by our model with 0.5 ach top-bottom mechanical ventilation after 12 hours of ventilation are $0.88,0.76,0.45,0.35$, and 0.27 for $\mathrm{C}_{\mathrm{o}}=0.8 \mathrm{~g}_{\mathrm{i}}, \mathrm{g}_{\mathrm{i}}, 2.5 \mathrm{~g}, 5 \mathrm{~g}, 25 \mathrm{~g}$, respectively. In Geller's (2002) measurements $\mathrm{PM}_{2.5-10}$ indoor concentrations were found markedly lower than those outdoors with the average indoor-to-outdoor mass concentration ratio equal to $0.66( \pm 0.27)$. Thus our calculated values for $\mathrm{PM}_{3-10}$ for 0.5 ach ventilation after 12 hours of ventilation also agree with the Geller's observations when the outdoor concentration is nearly equal to the indoor $\mathrm{PM}_{3-10}$ generation rate $\left(\mathrm{C}_{\mathrm{o}}=0.8 \mathrm{~g}_{\mathrm{i}}\right.$ to $2.5 \mathrm{~g}$; ; see table 5).

\section{PARTICULATE CONTROL IN INDUSTRY}

Various techniques are used to control air pollutants in industrial establishments depending on the size and properties of the PM (USEPA/BCES: module 6, 2010). These include

G ravity settling chamber: This can be used only for very large particles ( $\geq 75 \mu \mathrm{m}$ ).

M echanical collectors: These are used to remove particles larger than $5 \mu \mathrm{m}$. These equipments provide control efficiency of 50 to $90 \%$.

Particulate wet scrubbers: Their collection efficiency varies with particle size. It is good for $\mathrm{PM}_{5-10}(90-100 \%)$ but is very limited for $\mathrm{PM}<0.3 \mu \mathrm{m}$ for some types.

E lectr ostatic precipitators (ESPs): They can have very high efficiencies for $\mathrm{PM}_{1-10}$, but it decreases for UFPs and is minimum (20-60\%) for 0.1 to $0.5 \mu \mathrm{m}$ size range. For $\mathrm{PM}_{0.1}$ the collection efficiency of various ESPs is low-tomoderate (40-75\%).

Fabric filters: This technique is highly efficient for the entire particle size range of interest in air pollution control. The control efficiencies usually range from $99 \%$ to greater than $99.5 \%$ depending on the characteristics of the particulate matter and the fabric filter design.

\section{Conclusion}

The above studies and discussion provide us an understanding on how a deadly combination of solid fuels and poor ventilation triggers off an alarming increase of health damaging RPM in homes. Though dynamic and complex relationship exists between sources, air change rate and other variables but it is important to control indoor PM concentration. Awareness programs should therefore be undertaken to take proper measures to reduce RPM in indoor air so as to develop an environment which is suitable for its residents. The most effective control measure in residences and offices is a proper ventilation strategy. Ventilation acts differently on different particle sizes: the smaller the particles are, the more important the ventilation strategy is on airborne particle concentration. Ventilation plays a major role in controlling the indoor 
coarse particulate $\left(\mathrm{PM}_{>10}\right)$ irrespective of the outdoor concentration and ventilation rate. But the choice of inlet/ outlet locations and ventilation rate become important for finer particles. In case of fine particulate lower rate of ventilation is preferable.

\section{REFERENCES}

Abadie, M., Limam, K. and Allard, F. (2001). Indoor particle pollution: effect of wall textures on particle deposition. Building and Environment, 36: 821-827.

Abt, E., Suh, H.H., Catalano, P. and Koutrakis, P. (2000). Relative contribution of outdoor and indoor particle sources to indoor concentrations. Environmental Science and Technology, 34: 3579-3587.

Adgate, J.L., Ramachandran, G., Pratt, G.C., Walter, L.A., and Sexton, K. (2003). Longituderal variability in outdoor, indoor, and personal $\mathrm{PM}_{2.5}$ exposure. Atmospheric Environment, 36: 3255-3265.

Andresen, P.R., Ramachandran, G., Pai, P. and Maynard, A. (2005). Women's personal and indoor exposures to $\mathrm{PM}_{25}$ in Mysore, India: impact of domestic fuel usage. A tmospher ic Envir onment, 39: 5500-5508.

Balachandran, S., Meena, B.R. and Khillare, P.S. (2000). Particle size distribution and its elemental composition in the ambient air of Delhi. Environment International, 26: 49-54.

Balakrishnan, K., Parikh, J., Sankar, S., Padmavathi, R., Srividya, K., Venugopal, V., Prasad, S. and Pandey, V.L. (2002). Daily Average exposures to respirable particulate matter from combustion of biomass fuels in rural households of Southern India. Environmental H ealth Per spectives, 110: 1069.

Balakrishnan, K., Mehta, S., Kumar, S. and Kumar, P. (2003). Exposure to indoor air pollution: evidence from Andhra Pradesh, India. Regional Health F orum, WHO South-East Asia Region, 7(1).

Balakrishnan, K., Mehta, S., Kumar, P., Padmavathi, R., Sambandam, S., Kumar, K.S. and Smith, K.R. (2004). Indoor air pollution associated with household fuel use in India-An exposure assessment and modeling exercise in rural districts of Andhra Pradesh, India. World Bank Report, June 2004.

Ballard-Tremeer, G. and Mathee, A. (2000). Review of interventions to reduce the exposure of women and young children to indoor air pollution in developing countries; prepared for the WH O/U SAID consultation on Indoor Air Pollution and Health, 3- 4 May 2000, Washington D.C.

Ballester, F., Medina, S., Boldo, E., Goodman, P., Neuberger, M., Iniguez, C. and Kunzli, N.J. (2008). Reducing ambient levels of fine particulates could substantially improve health: a mortality impact assessment for 26 European cities. E pidemiol Community H ealth, 62: 98-105.

Bhanarkar, A.D., Rao, P.S., Gajghate, D.G and Nema, P. (2005). Inventory of $\mathrm{SO}_{2}, \mathrm{PM}$ and toxic metals emissions from industrial sources in Greater Mumbai, India. Atmospher ic Environment, 39: 3851-3864.

Bhandari, M. and Gupta, A. (2009). Radon in Indoor Air: An Indian Context. Indian J ournal of E nvironmental Protection, 29(4): 323-329.

Bhandari, M. and Gupta, A. (2010). Impact and assessment of volatile organic compounds in indoor air: A review. Invertis
J ournal of Science \& Technology, 3(1): 7-19.

Borja-Aburto, V.H., Eastillejos, M., Gold, D.R., Bierzwinski, S. and Looinis, D. (1998). Mortality and ambient fine particles in southwest Mexico City, 1993-1995. Environmental Health Per spectives, 106: 849-855.

Bouilly, J., Liman, K., Beghain, C. and Allard, F. (2005). Effect of ventilation strategies on particle decay rates indoors: an experimental and modeling study. Atmospheric Environment, 39: 4885-4892.

Brauer, M., Hirtle, R., Lang, B. and Ott, W. (2000). Assessment of indoor fine aerosol contributions from environmental tobacco smoke and cooking with a portable nephelometer. J ournal of Exposure Analysis and Environmental Epidemiology, 10: 136-144.

Clayton, C.A., Peritt, R.L., Pelizzari, E.D., Thomas, K.W., Whitmore, R.W., Wallace, L.A., Ozkaynak, H. and Spengler, J.D. (1993). Particle total exposure assessment methodology study: distribution of aerosol and elemental concentration in personal, indoor and outdoor air samples in a southern California community. J ournal of Exposure Analysis and Environmental E pidemiology, 3: 227-250.

CAI (2004). Clean Air Initiative: Global - Diesel particles - a health hazard Danish Ecological Council, page 20. www.cleanairnet.org/cai/1403/article-59346.html.

CPCB (2009). National Ambient Air Quality Standards. Central Pollution Control Board http://www.cpcb.nic.in/National ambient air quality standards. php.

Deb, M.K., Thakur, M., Mishra, R.K. and Bodhankar, N. (2002). Assessment of atmospheric arsenic level in airborne dust particulates of an urban city of Central India. Water, Air, and Soil Pollution, 140: 57-71.

Deshpande, J.M., and Holla, U.D. (2002). Impact of ambient air pollutants on the indoor air quality in Mumbai. 9th International Conference on Indoor Air Q uality and Climate, vol. 4: Jun 30-Jul 5 2002, Monterey, California.

Dionisio, K.L., Howie, S., Fornace, K.M., Chimah, O., Adegbola, R.A. and Ezzati, M. (2008). Measuring the exposure of infants and children to indoor air pollution from biomass fuels in The Gambia. Indoor Air, 18: 317-327.

Dockery, D.W., Pope, C.A., Xu, X., Splenger, J.D., Ware, J.H., Fay, M.E., Ferris Jr., B.G. and Speizer, F.E. (1993). An association between air pollution and mortality in six US cities. The new England J ournal of M edicine, 329: 17531759.

Fang, G.C., Chang, C.N., Wu, Y.S., Yang, C.J., Chang, S.C. and Yang, I.L. (2002). Suspended particulate variations and mass size distributions of incense burning at Tzu Yun Yen temple in Taiwan, Taichung. Science of the Total E nvironment, 299: 79-87.

Fang, G.C., Chang, C.N., Chu, C.C., Wu, Y.S., Pi-Cheng, F.P., Chang, S.C. and Yang, I.L. (2003). Fine (PM2.5), coarse (PM2.5-10), and metallic elements of suspended particulates for incense burning at Tzu Yun Yen temple in central Taiwan. Chemospher e, 51: 983-991.

Fogh, C.L., Byrne, M.A., Roed, J. and Goddard, A.J.H. (1997). Size specific indoor aerosol deposition measurements and derived I/O concentration ratios. Atmospher ic Environment, 31: 2193-2203.

Fung, Y.S. and Wong, L.W.Y. (1995). Apportionment of air pollution sources by receptor models in Hon Kong. 
Atmospheric Environment, 29: 2041-2048.

Gadhok, T.K. (Accessed in August 2008). Risks in Delhi: Environmental concerns. http://www.gisdevelopment.net/ application/natural hazards/overview/nho0019.htm.

Geller, M.D., Chang, M., Sioutas, C., Ostro, B.D. and Lipsett, M.J. (2002). Indoor/outdoor relationship and chemical composition of fine and coarse particles in the Southern California deserts. Atmospheric E nvironment, 36: 1099-1110.

Gupta, I. and Kumar, R. (2006). Trends of particulate matter in four cities in India. Atmospheric E nvironment, 40: 25522566.

Goyal, P. and Sidhartha (2003). Present scenario of air quality in Delhi: a case study of CNG implementation. Atmospheric Environment, 37: 5423-5431.

Jamriska, M., Morawska, L. and Clark, B.A. (2000). Effect of ventilation and filtration on sub-micrometer particles in an indoor environment. Indoor Air, 10: 19-26.

Jantunen, M., Hanninen, O., Koistinen, K. and Hashim, J.H. (2002). Fine PM measurements: personal and indoor air monitoring. Chemosphere, 49: 993-1007.

Jiang, R. and Bell, M.L. (2008). A comparison of particulate matter from biomass-burning rural and non-biomass-burning urban households in northeastern China. Envir on $\mathrm{H}$ ealth Perspect., 116: 907-14.

Jones, N.C., Thorton, C.A., Mark, D. and Harrison, R.M. (2000). Indoor/outdoor relationships of particulate matter in domestic homes with roadside, urban and rural locations. Atmospheric Environment, 34: 2603-2612.

Kagi, N., Fujii, S., Horiba, Y., Namiki, N., Ohtani, Y., Emi, H., Tamura, H., and Kim, Y.S. (2007). Indoor air quality for chemical and ultrafine particle contaminants from printers. Building and Environment, 42: 1949-1954.

Kim, Y.S. and Stock, T.H. (1986). House specific characterization of indoor and outdoor aerosols. Environment International, 12: 75-92.

Kittelson, D.B. (1998). Engines and nanoparticles: a review. J ournal of Aerosol Science, 29: 575-588.

Kumar, A.V., Patil, R.S. and Nambi, K.S.V. (2001). Source appointment of suspended particulate matter at two traffic junctions in Mumbai, India. Atmospheric Environment, 35: 4245-4251.

Lai, A.C.K. (2002). Particle deposition indoors: a review. Indoor Air, 12: 211-214.

Lai, H.K., Bayer-Oglesby, L., Colvile, R., Gotschi, T., Jantunen, M.J., Kunzli, N., Kulinskaya, E., Schweizer, C., and Nieuwenhuijsen, M.J. (2006). Determinants of indoor air concentrations of PM2.5, black smoke and $\mathrm{NO} 2$ in six European cities (EXPOLIS study). Atmospheric Environment, 40: 1299-1313.

Lee, S.C., Lam, S. and Fai, H.K. (2001). Characterization of VOCs, ozone, and $\mathrm{PM}_{10}$ emissions from office equipment in an environmental chamber. Building and Environment, 36: 837-842.

Liao, C.M., Chen, S.C., Chen, J.W. and Liang, H.M. (2006). Contributions of Chinese-style cooking and incense burning to personal exposure and residential PM concentrations in Taiwan region. Science of the Total Environment, 358: 7284.

Mage, D., Ozolins, G., Peterson, P., Webster, A., Ortherfer, R., Vandeveered, V. and Gwynne, M. (1996). Urban air pollution in mega cities of the world. Atmospheric Environment, 30: 681-686.

Mannix, R.C., Nguyen, K.P., Tan, E.W., Ho, E.E. and Phalen, R.F. (1996). Physical characterization of incense aerosols. Science of the Total E nvironment, 193: 149-158.

Moolgavkar, S.H., Luebeck, E.G. and Enderson, E.L. (1997). Air pollution and hospital admissions for respiratory causes in Minneapolis-St. Paul and Birmingham. E pidemiology, 8: 364-370.

Mundt, E. (2001). Non-buoyant pollutant sources and particles in displacement ventilation. Building and Environment, 36: 829-836.

Nazaroff, W.W., Gadgil, A.J. and Weschler, C.J. (1993). Critique of the use of deposition velocity in modeling indoor air quality: Modeling Indoor Air Quality and Exposure. STP 1205: American Society for Testing and Materials, Philadelphia, PA, pp. 81-104.

NILU (2002). Measurements of particulate matter: status report; EMEP/CCC-Report, 4/2002a: N orwegian Institute of air Research, Kjeller, Norway.

Nomura, Y., Hopke, P.K., Fitzgerald, B. and Meshah, B. (1997). Deposition of particles in a chamber as a function of ventilation rate. Aerosol Science and Technology, 27: 62-72.

Ozkaynak, H., Spengler, J.D., Ludwig, J.F., Butler, D.A., Clayton, C.A., Pellizzari, E.D. and Wiener, R.W. (1990). Personal exposure to particulate matter: findings from the particle total exposure assessment methodology pre-pilot study. Proceedings of the Fifth International C onference on Indoor Air Quality and Climate, Toronto, pp. 571-576.

Peng, R.D., Chang, H.H., Bell, M.L., McDermott, A., Zeger, S.L., Samet, J.M. and Dominici, F. (2008). Coarse particulate matter air pollution and hospital admissions for cardiovascular and respiratory diseases among medicare patients. J ournal of American M edical Association, 299(18): 2172-2179. http://jama.ama-assn.org/cgi/content/full/299/ $18 / 2172$.

Pentamwa, P. and Kim Oanh, N.T. (2008). Particulate matter and associated heptachlor in the indoor and outdoor air in Bangkok homes and vicinity, Thailand; in the Proceedings of the Better Air Q uality (BAQ), Workshop: 12-14 N ovember 2008 Bangkok, Thailand.

Pope, C.A., Burnett, R.T., Thun, M.J., Calle, E.E., Krewski, D., Ito, K. and Thurston, G.D. (2002). Cancer, cardiopulmonary mortality, and long-term exposure to fine particulate air pollution. J ournal of American Medical Association, 287(9): 1132-1141. http://jama.ama-assn.org/ cgi/reprint/287/9/1132.

Quackenboss, J.J., Lebowitz, M.D. and Crutchfield, C.D. (1989). Indoor - outdoor relationships for particulate matter: exposure classifications and health effects. Environment International, 15: 353-360.

Ratan, V. and Kumar, S. (2005). Air quality index for urban areas. Indian J ournal of E nvironmental Protection, 25: 743 752.

Rojas-Bracho, L., Suh, H., and Koutrackis, P. (2000). Relationships among personal, indoor and outdoor fine and coarse particle concentrations for individuals with COPD. Journal of Exposure Analysis and Environmental Epidemiology, 10: 294-306.

Saksena, S. and Uma, R. (2008). Longitudinal study of indoor 
particulate matter and its relationship to outdoor concentrations in New Delhi, India. Indoor and Built Environment, 17: 543-551.

Samet, J.M., Dominici, F., Currierso, F.C., Coursac, I. and Zeger, S.L. (2000). Fine particulate air pollution and mortality in 20 US cities. The N ew England J ournal of M edicine, 343: 1742-1749.

Schwartz, J. (1994). $\mathrm{PM}_{10}$, ozone and hospital admissions for the elderly in Minneapolis-St. Paul Minnesota. Archives of Environmental Health, 49: 366-374.

Schwartz, J., Dockery, D.W. and Neas, L.M. (1996). Is daily mortality associated specifically with fine particles. J ournal of Air and Waste M anagement Association, 46: 927-939.

Seinfeld, J. and Pandis, S. (1998). From air pollution to climate change, Atmospheric Chemistry and Physics. John Wiley, New York.

Sharma, M. and Maloo, S. (2005). Assessment of Ambient air $\mathrm{PM}_{10}$ and $\mathrm{PM}_{2.5}$ and characterization of $\mathrm{PM}_{10}$ in the city of Kanpur, India. A tmospheric Environment, 39: 6015-6026.

Sharma, M., Pandey, R., Maheshwari, M., Sengupta, B., Misra, A. and Shukla, B.P. (2003). Air quality index and its interpretation for the city of Delhi. International J ournal on Energy for Clean Environment, 4(3): 269-283.

Sivertsen, B. (2002). Presenting air quality data. NILU -F 6/ 2002, National Training course on Air Q uality M onitoring and M anagement, Norwegian Institute for Air Research, Kjeller, Norway.

Smith, D.J.T., Roy, M.H., Luhana, L., Casimiro, A.P., Castro, L.M., Tariq, M.N., Hayat, S. and Quraishi, T. (1996) Concentrations of particulate airborne polycyclic aromatic hydrocarbons and metals collected in Lahore, Pakistan. Atmospheric Environment, 30: 4031-4040.

TERI (2001). Review of past and on-going work on urban air quality in India. http://siter esources.worldbank.org/ PAKISTANEXTN/Resources/U rbanAir/PastAndOngoing.pdf : 73-82.

Thatcher, T.L., Lai, A.C.K. and Moreno-Jackson, R. (2002). Effects of room furnishings and air speed on particle deposition rates indoors. Atmospheric Environment, 36: 1811-1819.

USEPA (2010). BCES: module6: Air Pollutants and Control Techniques - Particulate Matter. http://www.epa.gov/apti/ bces/module6/matter/control/control.htm. as updated on August 09, 2010.

USEPA (1995). Air quality criteria for particulate matter vol. II. External Review Draft. EPA/600/AP-95/001b, US Environmental Protection Agency, Office of Research and Development, Washington DC.

USEPA (1996). Air quality criteria for particulate matter. EPA/ 600/P-95/001a, US Environmental Protection Agency, Office of Research and Development, Washington, DC.

Vedal, S. (1997). Ambient particles and health: lines that divide. J ournal of Air and Waste M anagement Association, 47: 551581.

Venkataraman, C. and Kulkarni, P. (2000). Atmospheric polycyclic aromatic hydrocarbons in Mumbai, India. Atmospheric Environment, 34: 2785-2790.

Wallace, L.A. (1996). Indoor particles: a review. J ournal of Air Waste M anagement Association, 46: 98-126.

Wensing, M., Schripp, T., Uhde, E. and Salthammer, T. (2008). Ultra-fine particles release from hardcopy devices: Sources, real-room measurements and efficiency of filter accessories. Science of the Total E nvironment, 407: 418-427.

World Bank (2007). World Development Indicators; WDI07 section3: indd, pp.174-175. http://siter esources. worldbank. org /D ATASTATISTICS/Resources/table3_13.pdf.

WHO (2002). World H ealth Report: Reducing risks, promoting healthy life; World Health Organization, Geneva pages xv, 69.

Yeh, H.C., Phalen, R.F. and Raabe, O.G. (1976). Factors influencing the deposition of inhaled particles. Environmental H ealth Per spectives, 15: 147-156.

Zhao, B., Zhang, Y., Xianting, L., Xudong, Y. and Dongtao, H. (2004). Comparison of indoor aerosol particle concentration and deposition in different ventilated rooms by numerical method. Building and E nvironment, 39: 1-8. 